\title{
Ten-year cardiovascular risk assessment in university students
}

\author{
M Uvacsek ${ }^{1}$, Zs Kneffel ${ }^{2}$, M Tóth ${ }^{1}$, AW Johnson ${ }^{3}$, P Vehrs ${ }^{3}$, JW Myrer ${ }^{3}$, R Hager $^{3}$ \\ ${ }^{1}$ Department of Health Sciences and Sport Medicine, Faculty of Physical Education and Sport Science, \\ Semmelweis University, Budapest, Hungary \\ ${ }^{2}$ Qatar University, Sport Science Program, Doha, Qatar \\ ${ }^{3}$ Brigham Young University, Provo, Utah, USA
}

Received: July 18, 2013

Accepted after revision: February 21, 2014

\begin{abstract}
Cardiovascular disease (CVD) is responsible for more than half of all deaths in the European region. The aim of the study was to compare body composition, blood pressure, total cholesterol (TC) and high density lipoprotein cholesterol (HDL-C), family history, activity behaviors, and the 10-year risk of having a heart attack between 166 university students (21.62 $\pm 2.59 \mathrm{yrs})$ from Utah (USA) and 198 students (22.11 \pm 2.51 yrs) from Hungary. Ninetytwo percent of the Hungarian students and $100 \%$ of the Utah students had an estimated 10-year Framingham risk score of $1 \%$ or less. The high prevalence of low risk was primarily due to the young age of study participants, healthy body composition and non-smoking behavior. Hungarians who had higher 10-year risk of heart attack had significantly higher waist hip ratio (WHR), TC, diastolic blood pressure (DBP) and were smokers compared to those Hungarians with lower risk. The self-reported physical activity levels between the two groups of students were not different. In conclusion the young men and women who participated in this study were, for the most part healthy; however the smoking habits and the lower physical activity of the Hungarian students likely elevated their risk of CVD.
\end{abstract}

Keywords: cardiovascular risk, university students, smoking, body mass index, blood lipids

Cardiovascular disease (CVD) is one of the major causes of mortality in economically developed countries as well as in transitional economies. There is also a trend towards an increasing prevalence of CVD in developing countries (14). Healthy lifestyles, such as eating a prudent diet, regular physical activity, and not smoking are the most important preventive measures. Good health-related habits are learned early in life and have been associated with parental and peer group influences, and are strongly associated with socio-economic status and education $(1,8)$. Cardiovascular risk prediction calculations use biological characteristics (age, gender) and modifiable risk factors (blood pressure, lipid levels, and lifestyle conditions) to assess and predict CVD risk. Although the sensitivity and specificity of the risk assessment tools are low in young adults, especially at younger ages where they sometimes underestimate the risk, such tools are useful in screening young adults for increased risk of CVD (11). The socio-economic background of CVD has found that males between 20 and 64 years of age in semi- and unskilled occupations have a risk of premature death from CVD that is three times higher than those working in professional and managerial positions. According to Karlamangla et al. (6) individuals with high overall cardiovascular risk in midlife can be identified by their relatively higher values of risk factors in younger ages and that socio-economic differences

Corresponding author: Martina Uvacsek, $\mathrm{PhD}$

Faculty of Physical Education and Sport Science, Semmelweis University, Budapest, Hungary

Phone: +36 20 9974825; Fax: +361 4879275; E-mail: martina@tf.hu 
in cardiovascular risk starts accumulating early in life. There is still limited information about CVD risk among university aged students; therefore it is important to gather risk related data on this younger educated population in order to provide education about reducing the risk of CVD and improving health status later in life.

The purpose of this study was to compare body mass index (BMI), percent body fat $(\% \mathrm{BF})$, blood pressure, blood lipids, family history, physical activity behaviors, and the 10year risk of having a heart attack between university students from Utah, USA and Budapest, Hungary.

\section{Materials and Methods}

\section{Participants and settings}

One hundred and ninety-eight university students in Hungary [men $(n=76)$; women $(n=$ 122) mean age $=22.11 \pm 2.51 \mathrm{yrs}$ ] and 166 students from USA [men $(n=70)$; women $(n=$ 96) mean age $=21.62 \pm 2.59 \mathrm{yrs}]$ volunteered to participate in this study. Participants were recruited through announcements in the Department of Health Sciences and Sport Medicine at Semmelweis University and in the Human Performance Research Center of the Department of Exercise Sciences at Brigham Young University. Participants were excluded from the study if they were pregnant or were not able to fast for 8 to 12 hours prior to the data collection. This study was reviewed and approved by the Institutional Review Board (IRB) for Human Subjects at Brigham Young University and Semmelweis University. All study participants provided written informed consent prior to participation in the study.

\section{Body dimensions and demographics}

Each participant self-reported their age, gender, marital status, family history, smoking history, physical activity, signs and symptoms and presence of known cardiovascular, metabolic and pulmonary diseases by completing a brief pre-participation health history questionnaire.

Each participant's height was measured to the nearest one-quarter inch $(0.6 \mathrm{~cm})$ using a calibrated wall scale. Weight was measured to the nearest tenth of a pound $(0.2 \mathrm{~kg})$, using a digital scale (Healthometer Professional, Model 349KLX/320KL, Sunbeam Products, Inc., Boca RatonFL33431, USA). Body mass index $\left(\mathrm{kg} / \mathrm{m}^{2}\right)$ was calculated from measures of height and weight after being converted to meters and kilograms, respectively.

Waist and hip circumferences were measured as described by the American College of Sports Medicine to the nearest quarter inch $(0.6 \mathrm{~cm})$ while in the standing position using a spring-loaded Gulick tape measure. Waist-to-hip ratio (WHR) was calculated by dividing the recorded waist circumference by the recorded hip circumference. The $\% \mathrm{BF}$ was measured with a hand-held bioelectrical impedance analyzer (OMRON model HBF306; OMRON Healthcare Inc., Vernon Hills, IL, USA).

\section{Blood pressure and blood tests}

Resting blood pressure was measured on the left arm using an automated blood pressure monitor (Omron Model HEM-780, Omron Healthcare, Inc., Bannockburn, Illinois, USA). Three consecutive blood pressure measurements were made in the seated position after at least 5 minutes of rest. The average systolic (SBP) and diastolic blood pressure (DBP) was recorded.

Participants were instructed to fast 8-12 hours before having their blood drawn. Approximately, $17.5 \mathrm{ml}$ of blood were drawn by trained phlebotomists. Assays included a 
lipid panel which included TC, HDL-C, low-density lipoprotein cholesterol (LDL-C), very low-density lipoprotein cholesterol (VLDL-C), and triglycerides.

\section{Physical activity questionnaires' (physical activity rating scale and perceived functional ability scale)}

Participants responded to a question included in the pre-participation questionnaire which asked if they met the recommended minimal amount of physical activity (at least 30 minutes of moderate-intensity physical activity) most of the days of the week. Answering "No" to this question resulted in being classified as being sedentary.

Participants also self-reported their level of physical activity over the previous month using a modified Physical Activity Rating scale (PA-R) (2, 4). Participants self-reported their perceived ability to walk, jog, or run a distance of 1 mile $(1.6 \mathrm{~km})$ and 3 miles $(4.8 \mathrm{~km})$ at a comfortable pace using a 13 point Perceived Functional Ability (PFA) scale $(2,4)$. The responses to both PFA questions were summed to generate the PFA score.

\section{Cardiovascular risk scoring system}

The Framingham Risk Score has been validated in the USA and the system gives an estimate of the probability that person will develop cardiovascular disease within next 10 years. Individuals with low risk have $10 \%$ or less CVD risk at ten years, with intermediate risk 10 $20 \%$, and with high risk $20 \%$ or more. The 10 -year CVD risk was estimated online using the following web page: http://hp2010.nhlbihin.net/atpiii/calculator.asp. The risk assessment tool used the following information of subjects: age, gender, total cholesterol, HDL cholesterol, smoking habit, systolic blood pressure and medication to treat high blood pressure.

\section{Statistical analyses}

Descriptive statistics were calculated using the STATISTICA software version 11.0 (Stat Soft., Inc., USA). Anthropometric and physiological variables of Hungarian and Utah males and females were compared by factorial analysis of the variance (ANOVA). Student's $t$-test was used for analyzing the differences of Hungarian subgroups with a risk score $1 \%$ or less vs. those with a risk score of greater than $1 \%$. Statistical significance was set at $p<0.05$.

\section{Results}

Personal characteristics and self-reported physical activity levels of all participants are included in Table I. Male participants were, as was expected, significantly taller and heavier and had a higher BMI than their female counterparts. According to the BMI categories $11 \%$ of the Hungarian females and $12 \%$ of the USA females were overweight or obese and $27 \%$ and $30 \%$ of the male students had BMI $\geq 25$ in Hungary and USA. There were no significant differences in the WHR between males and females and all of the students' WHR were considered to be within a healthy level. The \%BF values of Hungarian males and females were significantly lower than those of their American counterparts. The body composition of the participants in Hungary and in the USA was generally healthy. The self-reported physical activity regarding activity or sedentary behavior showed a large difference in activity levels of students in Hungary compared to those from the USA; however the special PFA questionnaire showed a closer relationship to the anthropometric values. Based on the PFA scores the Hungarians were generally more active than their counterparts in USA, the least active group was the USA female students', however the most active were the USA males. 
Blood lipids, blood pressure and the 10-year cardiovascular risk are shown in Tables II and III. The online risk assessment tool based on the participants' age, gender, total cholesterol, HDL cholesterol, smoking habit, systolic blood pressure and use of medication to treat of high blood pressure predicted generally low risk of CVD in the participants. The Hungarian students had significantly higher TC and HDL-C levels than the students from the USA. None of the USA students had cardiovascular risk computed based on the Framingham Risk Score higher than $1 \%$, while $8 \%$ of the Hungarians had a risk score greater than $1 \%$. Interesting result is that only $16 \%$ of the Hungarian students and none of the USA students were smokers. Analyzing the family histories of CVD we found that only 3\% of the Hungarians and $4 \%$ of the USA students had cardiovascular disease in their families.

Further analysis indicated that the Hungarian students with higher than 1\% risk had significantly higher WHR, and TC levels, and diastolic blood pressure and that all of them were smokers. Students with higher CVR also had lower HDL C levels and higher SBP but these differences were not statistically significant (Table IV).

Table I. The anthropometric characteristics, perceived functional ability score (PFA) (mean \pm SD) and the prevalence of sedentary and active behavior of the students from USA and Hungary

\begin{tabular}{|l|c|c|c|c|c|}
\hline & USA females & HUN females & USA males & HUN males & $p$ \\
\hline Valid $N$ & 96 & 122 & 70 & 76 & \\
\hline Age & $20.39 \pm 2.19$ & $21.96 \pm 2.07$ & $23.30 \pm 2.10$ & $22.35 \pm 3.08$ & $\mathrm{a}, \mathrm{b}, \mathrm{c}$ \\
\hline Height $(\mathrm{m})$ & $1.66 \pm 0.06$ & $1.68 \pm 0.06$ & $1.78 \pm 0.06$ & $1.80 \pm 0.07$ & $\mathrm{a}, \mathrm{c}, \mathrm{d}$ \\
\hline Weight $(\mathrm{kg})$ & $62.28 \pm 3.08$ & $61.41 \pm 7.94$ & $75.56 \pm 14.51$ & $76.38 \pm 11.10$ & $\mathrm{c}, \mathrm{d}$ \\
\hline BMI $\left(\mathrm{kg} / \mathrm{m}^{2}\right)$ & $22.49 \pm 3.08$ & $21.49 \pm 2.44$ & $23.58 \pm 4.16$ & $23.36 \pm 2.59$ & $\mathrm{a}, \mathrm{c}, \mathrm{d}$ \\
\hline WHR & $0.72 \pm 0.04$ & $0.71 \pm 0.03$ & $0.80 \pm 0.04$ & $0.79 \pm 0.05$ & $\mathrm{NS}$ \\
\hline Body Fat $(\%)$ & $22.77 \pm 5.09$ & $19.24 \pm 4.93$ & $13.63 \pm 6.00$ & $11.30 \pm 4.92$ & $\mathrm{a}, \mathrm{b}, \mathrm{c}, \mathrm{d}$ \\
\hline Overweight or obese (\%) & 12 & 11 & 30 & 27 & $\mathrm{c}, \mathrm{d}$ \\
\hline $\begin{array}{l}\text { Sedentary (less than } 30 \mathrm{~min} \\
\text { MVPA/day) }(\%)\end{array}$ & 19 & 50 & 14 & 46 & $\mathrm{a}, \mathrm{b}$ \\
\hline PFA score & $16.48 \pm 4.55$ & $17.69 \pm 3.56$ & $18.78 \pm 5.10$ & $18.52 \pm 4.72$ & $\mathrm{c}$ \\
\hline
\end{tabular}

a = significant difference between USA females and Hungarian females;

$\mathrm{b}=$ significant difference between USA males and Hungarian males;

$\mathrm{c}=$ significant difference between USA females and USA males;

$\mathrm{d}=$ significant difference between Hungarian females and Hungarian males;

NS $=$ not significant

Table II. The blood lipids and the systolic blood pressure $($ mean \pm SD) of USA and Hungarian students

\begin{tabular}{|l|c|c|}
\hline & USA (BYU students) & Hungary (SU students) \\
\hline TC $(\mathrm{mg} / \mathrm{dL})$ & $152.40 \pm 30.24$ & $176.12 \pm 37.84^{*}$ \\
\hline $\mathrm{HDL}-\mathrm{C}(\mathrm{mg} / \mathrm{dL})$ & $56.93 \pm 15.52$ & $66.67 \pm 17.24^{*}$ \\
\hline $\mathrm{TC} / \mathrm{HDL}-\mathrm{C}$ & $2.68 \pm 1.95$ & $2.64 \pm 2.19$ \\
\hline $\mathrm{SBP}(\mathrm{mmHg})$ & $112.68 \pm 11.59$ & $114.65 \pm 13.70$ \\
\hline
\end{tabular}

Total $\mathrm{C}=$ total cholesterol; HDL C $=$ HDL cholesterol; SBP = systolic blood pressure;

*significant difference between groups 
Table III. The results of 10 years cardiovascular risk assessment, smokers' rate and family history of CVD (\%) for USA and Hungarian students

\begin{tabular}{|l|c|c|c|}
\hline & USA (BYU students) & Hungary (SU students) & Risk score \\
\hline CVR below 1\% & 100 & 92 & \\
\hline CVR above 1\% & 0 & 7 & $\begin{array}{c}\text { Smoking habit } \\
\text { TC } \geq 160 \mathrm{mg} / \mathrm{dL} \\
\mathrm{HDL}-\mathrm{C}<50 \mathrm{mg} / \mathrm{dL} \\
\text { SBP }>120 \mathrm{Hgmm}\end{array}$ \\
\cline { 1 - 3 } CVR 2\% & 0 & 0.5 & 0.5 \\
\cline { 1 - 3 } CVR 3\% & 0 & 16 & \\
\hline Smokers \% & 0 & 3 & \\
\hline Family history of CVD & 4 & &
\end{tabular}

$\mathrm{CVR}=$ cardiovascular risk; $\mathrm{TC}=$ total cholesterol; HDL-C $=$ high density lipoprotein cholesterol; $\mathrm{SBP}=$ systolic blood pressure $\mathrm{CVD}=$ cardiovascular disease

Table IV. The differences between Hungarian subgroups low CVR vs. higher CVR (mean $\pm \mathrm{SD})$

\begin{tabular}{|l|c|c|c|}
\hline & $\begin{array}{c}\text { Hungary (SU students) } \\
\text { CVR below 1\% }(\boldsymbol{N}=\mathbf{1 7 6})\end{array}$ & $\begin{array}{c}\text { Hungary (SU students) } \\
\text { CVR=1\% or more }(\boldsymbol{N}=\mathbf{1 5})\end{array}$ & $\boldsymbol{p}$ \\
\hline Age & $22.09 \pm 2.40$ & $21.86 \pm 2.26$ & 0.727 \\
\hline Height $(\mathrm{m})$ & $1.73 \pm 0.08$ & $1.77 \pm 0.11$ & 0.113 \\
\hline Weight $(\mathrm{kg})$ & $67.08 \pm 12.01$ & $70.61 \pm 8.84$ & 0.267 \\
\hline BMI $\left(\mathrm{kg} / \mathrm{m}^{2}\right)$ & $22.24 \pm 2.71$ & $22.56 \pm 2.21$ & 0.652 \\
\hline WHR & $0.74 \pm 0.05$ & $0.78 \pm 0.07$ & $\mathbf{0 . 0 0 3}$ \\
\hline Body fat $(\%)$ & $16.41 \pm 6.20$ & $13.26 \pm 7.42$ & 0.064 \\
\hline TC & $176.44 \pm 34.43$ & $202.33 \pm 46.61$ & $\mathbf{0 . 0 0 7}$ \\
\hline HDL $-\mathrm{C}$ & $66.05 \pm 16.04$ & $59.13 \pm 19.37$ & 0.116 \\
\hline SBP $(\mathrm{mmHg})$ & $114.40 \pm 14.19$ & $120.26 \pm 7.52$ & 0.116 \\
\hline DBP $(\mathrm{mmHg})$ & $71.07 \pm 7.94$ & $76.06 \pm 5.54$ & $\mathbf{0 . 0 1 8}$ \\
\hline
\end{tabular}

$\mathrm{CVR}=$ cardiovascular risk; $\mathrm{TC}=$ total cholesterol; HDL-C $=$ high density lipoprotein cholesterol; $\mathrm{SBP}=$ systolic blood pressure; $\mathrm{DBP}=$ diastolic blood pressure; $p$ values lower than 0.05 are presented in bold

\section{Discussion}

The increasing prevalence of obesity in children, adolescents and adults worldwide has become a major health issue for many countries. The data from this study suggest that even educated university students are not immune to this epidemic. In studies such as ours, university students' BMI, the prevalence of overweight and obesity and the \%BF are usually investigated with the other cardiovascular risk factors. Bleske et al. (1) compared developed and developing nations' students and their students from USA (22.9 \pm 3.2$)$ and India (21.5 \pm 2.7) had lower BMI averages than our participants but students from Syria (25.2 \pm 2.7$)$ had higher. Neville et al. (10) presented UK students' data where the BMI were close to our results but their $\% \mathrm{BF}$ was higher (women $=26.7 \pm 6.9 \%$ and $\mathrm{men}=15.8 \pm 5.7 \%$ ). The same results were found by Zemdegs et al. (15) from Brazil, where the women-students' \%BF was $29.6 \pm 6.2 \%$ and that of the men' was $17.9 \pm 4.9 \%$. High prevalence of overweight or obesity was found in university students from Jerusalem where $40 \%(31+9)$ of the males and 19\% $(15+4)$ of the females had BMI $\geq 25(13)$. 
Maintaining a physically active lifestyle is an important modifiable behavior that has a positive impact on health and it reduces the risk of CVD. Analyzing the activity and sedentary behavior of the participants in our study, $50 \%$ of the Hungarians but only $20 \%$ of the USA students were considered to be severely inactive. Severe physical inactivity of students of other ethnic populations was reported as well. Tayem et al. (13) presented that $26.9 \%$ of the students from Jerusalem had severe physical inactivity, as indicated by less than 30 min daily activity. The women's physical activity is generally reported to be lower than men's. Molina et al. (9) presented that only $13.8 \%$ of the female Spanish students reported significant physical activity. The physical inactivity was also high (35.7\%) in students from Brazil (15), sedentary lifestyle was presented in $37.8 \%$ of the women and in $27.3 \%$ of the men. Martinez et al. (8) from Chile presented that $88 \%$ of the university students had sedentary habits. Freitas et al. (3) have found that most college students $(70.2 \%)$ were classified as sedentary. Hernández-Escolar et al. (5) found similar high sedentary behavior (64.1\%) at students from Bolivar. Bleske et al. (1) published that university students from India were less likely to engage in physical activity $(20.2 \%)$ than students from USA $(90.7 \%)$ or Syria $(68.8 \%)$. The gender difference in activity was significant in our USA students from Utah but was not significant in our Hungarian sample, however generally the man's activity was higher. Neville et al. (10) also compared the activity of the UK students and found non-significant difference between men and women; however men exercise was $3.17 \pm 2.69 \mathrm{~h} /$ week while that of women was $2.43 \pm 1.87 \mathrm{~h} /$ week.

The cardiovascular risk is strongly associated with blood lipid levels. Recent studies indicate that the trend of higher blood lipid levels in university populations may increase the risk of CVD in some countries. Martínez et al. (8) found in Chile that $19 \%$ of the university students had high LDL cholesterol levels and $40 \%$ had high blood pressure. The total cholesterol of our investigated USA students were similar to other students' lipid levels from other student groups, such as the University of Michigan (156 \pm 31$)$, students from Syria (153 \pm 28 ) (1) or students from Brazil (155.28 \pm 2.376$)$ (3). The Hungarian students had significantly higher total cholesterol level $(176.12 \pm 37.84)$ compared to the USA sample and to other student samples, but their significantly high HDL cholesterol level $(66.67 \pm 17.24)$ explains these results. Increased physical activity is able to elevate the HDL cholesterol levels, however; both of our samples were generally active, only the Hungarians had higher HDL cholesterol level. According to the different lipid studies of university students the HDL cholesterol levels generally fluctuate between $35 \mathrm{mg} / \mathrm{dL}$ and $58 \mathrm{mg} / \mathrm{dL}(1,3,15)$. The prevalence of hypertensive students is often part of the cardiovascular risk studies, Tayem et al. (13) found that $29.3 \%$ of the students were pre-hypertensive or hypertensive in Jerusalem, Bleske et al. (1) published that in India it was only $21.8 \%$ but in Syria and USA it was higher $33.8 \%$ and $30.9 \%$, respectively. In our study only $8 \%$ of the Hungarians had higher than $1 \%$ CVR assessment and had higher systolic and diastolic blood pressure.

Unhealthy habits like smoking can account for $10 \%$ of cardiovascular disease worldwide. The smoking habits of the university students are frequently investigated, and Mackowiak et al. (7) have found that the smoking habits of university students can modify plasma lipid profile and elevate the CVR, especially in males. Analyzing results from multiple studies, the prevalence of currents smokers was varied, the highest rate was found in Syria (43\%), also a high prevalence was found in Spain (31.7\%) and in Croatia (30.4\%). Additionally, 29.3\% of students smoke in Jerusalem, 28\% in Chile, 23.9\% in Bolivia, 10.7\% in Brazil and $6.2 \%$ in USA at University of Michigan and $1.7 \%$ in India $(1,5,8,9,12,13,15)$. Comparing our results to these studies we can state that the involved students' health-related habits and life- 
style were good in comparison and in certain ways they were better than generally observed in other populations. Healthy lifestyle choices of increased physical activity, balanced diet and cessation of smoking lead to improved well-being and quality of life, while also decreasing risk of CVD. Decreased prevalence of CVD will in turn decrease the medical care and resource demands on society.

This study has some limitations, the socioeconomic background and the eating habits, consumed fat were not examined, however these factors are strongly associated with the blood lipid levels and body dimensions.

\section{Conclusion}

The students from Utah, USA had better health-related attitudes than Hungarians which might be explained by these students' better health practices. In conclusion, the young men and women in both Hungary and Utah who participated in this study were, for the most part, healthy however the Hungarian population's smoking habit and physical inactivity elevated their CVR. University students should be encouraged to adopt healthier lifestyle practices of increased physical activity and cessation of smoking in order to decrease the risk of CVD. Ideally, these healthy lifestyle choices would be practiced throughout life and lead to overall better quality of life and a decrease in the expenditure of medical, economic and governmental resources needed to treat the consequences of CVD later in a person's life.

\section{REFERENCES}

1. Bleske BE, Erickson SR, Fahoum S, Devarakonda KR, Welage LS, Koudmani M, Pantham N, Edwin SB, Devarakonda S, Shea MJ, Martha S, Khalidi N: Cardiovascular risk among university students from developed and developing nations. Open Cardiovasc. Med. J. 5, 117-122 (2011)

2. Bradshaw DI, George JD, Hyde A, LaMonte MJ, Vehrs PR, Hager RL, Yanowitz FG: An accurate $\mathrm{VO}_{2}$ max nonexercise regression model for 18-65-year-old adults. Res. Q. Exerc. Sport 76, 426-432 (2005)

3. Freitas RWJr, Araújo MF, Marinho NB, Vasconcelos HC, Lima AC, Pereira DC, Almeida PC, Zanetti ML, Damasceno MM: Prevalence of the metabolic syndrome and its individual components in Brazilian college students. J.Clin. Nurs. 22, 1291-1298 (2013)

4. George JD, Stone WJ, Burkett LN: Non-exercise $\mathrm{VO}_{2} \max$ estimation for physically active college students. Med. Sci. Sports Exerc. 29, 415-423 (1997)

5. Hernández-Escolar J, Herazo-Beltrán Y, Valero MV: The frequency of cardiovascular disease-associated risk factors in a university student population. Rev. Salud. Publica 12, 852-864 (2010)

6. Karlamangla AS, Singer BH, Williams DR, Schwartz JE, Matthews KA, Kiefe CI, Seeman TE: Impact of socioeconomic status on longitudinal accumulation of cardiovascular risk in young adults: the CARDIA Study (USA). Soc. Sci. Med. 60, 999-1015 (2005)

7. Mackowiak K, Nowicki M, Wysocka E, Brozek A, Torlinski L: The impact of tobacco smoking on the selected risk factors for cardiovascular disease in students of Poznan University of Medical Sciences. Przegl. Lek. 69, 819-823 (2012)

8. Martinez SMA, Leiva OAM, Sotomayor CC, Victoriano RT, Von Chrismar PAM, Pineda BS: Cardiovascular risk factors among university students. Rev. Med. Chil. 140, 426-435 (2012)

9. Molina AJ, Varela V, Fernández T, Martín V, Ayán C, Cancela JM: Unhealthy habits and practice of physical activity in Spanish college students: the role of gender, academic profile and living situation. Adicciones 24, 319-327 (2012)

10. Neville MM, Geppert J, Min Y, Grimble G, Crawford MA, Ghebremeskel K: Dietary fat intake, body composition and blood lipids of university men and women. Nutr. Health 21, 173-185 (2012)

11. O’Donnell CJ, Elosua R: Cardiovascular risk factors. Insights from Framingham heart study. Rev. Esp. Cardiol. $61,299-310(2008)$ 
12. Reiner Z, Sonicki Z,Tedeschi-Reiner E: The perception and knowledge of cardiovascular risk factors among medical students. Croat. Med. J. 53, 278-284 (2012)

13. Tayem YI, Yaseen NA, Khader WT, Abu Rajab LO, Ramahi AB, Saleh MH: Prevalence and risk factors of obesity and hypertension among students at a central university in the West Bank. Libyan J. Med. 7 (2012)

14. Tunstall-Pedoe H, Vanuzzo D, Hobbs M, Mähönen M, Cepaitis Z, Kuulasmaa K, Keil U: Estimation of contribution of changes in coronary care to improving survival, event rates, and coronary heart disease mortality across the WHO MONICA Project populations. Lancet 355, 688-700 (2000)

15. Zemdegs CSJ, Barreto CL, Coelho CL, Pimentel DG, Hirai TA, Sachs A: Lipid profile and cardiovascular risk factors among first-year Brazilian university students in Sao Paulo. Nutr. Hosp. 26, 553-559 (2011) 